\title{
Concentrations of Trace Elements in Different types of Gallstones and Their Effects on Gallstone Formation
}

\section{Yue ZHANG ${ }^{1}$, Chong-yu ZHANG ${ }^{2}$, Da GUO ${ }^{2}$, Xiao-jun HUANG ${ }^{1}$, Jun-fa XUE ${ }^{2}$ and Jian-ming OUYANG ${ }^{2}$}

\author{
${ }^{1}$ Department of Hepatobiliary and Pancreas Surgery, Second Clinical Medical \\ College of Jinan University (Shenzhen People's Hospital), Shenzhen, Guangdong \\ Province, China. \\ ${ }^{2}$ Department of Chemistry, Jinan University, Guangzhou 510632, China \\ szrmyy@126.com (Y. Zhang), toyjm@jnu.edu.cn (J-M Ouyang)
}

${ }^{*}$ Corresponding author

Keywords: Gallstones, Trace Element, ICP-AES, Cholesterol, Bile Pigment.

\begin{abstract}
Purpose: To study the concentrations of trace metals and nonmetals elements in different types of gallstones (cholesterol-, pigment-, mixed- and calcium carbonate type) and to explore the formation mechanisms of gallstones. Method: Inductively coupled plasma emission spectrometer (ICP-AES) was used to determine the concentrations of calcium, manganese, magnesium, iron, copper, zinc, sulfur, and phosphorus. Results: Calcium, copper, sulfur and phosphorus play important roles in the formation of pigment stones. High concentrations of $\mathrm{Cu}^{2+}$ and $\mathrm{Ca}^{2+}$ ions can coordinate with bilirubin to form calcium bilirubinate and copper bilirubinate, respectively; phosphorus and sulfur suggest the presence of proteins in gallstones, and some proteins (such as mucin) can promote the formation of gallstones. Conclusions: The contents of metal and nonmetal elements in gallstones can accurately be detected using ICP-AES. The formation of different types of gallstones is closely related to the difference of these elements. This study is of great significance to reveal the cause of gallstones formation.
\end{abstract}

\section{Introduction}

Gallstone disease is a common disease of biliary system, and its incidence is increasing [1,2]. The incidence of gallstones in Chinese is about 4.21 11.0\%. At present, the pathogenesis of gallstones is not clear yet [3]. The chemical composition of gallstones is complex. Cholesterol, bilirubin, calcium salts, bile salts, proteins, and the salts of fatty acids are the common chemical components. Meanwhile, it contains inorganic metal ions and so on. Copper bilirubinate can be founded in black pigment stones.

X-ray diffraction, elemental analysis, Raman spectroscopy, electron spin resonance spectroscopy, atomic absorption spectroscopy, thermogravimetric spectrum and other spectroscopic methods are widely used to study the composition of gallstones [4, 5]. It was showed that the stones not only contained a variety of organic substances, but also contained a variety of metal ions such as calcium, copper, zinc magnesium, iron, aluminum, manganese, and sodium, etc. There are complex interactions among the components. The composition of gallstones and their distribution in body are the keys to explore the cause of gallstons disease. The formation of gallstones is closely related to many factors including the thermodynamics of bile, the kinetics of gallbladder, and the imbalance of the promoting or inhibiting factors in bile. The formation of 
gallstones can be affected by the change of bile, gallbladder emptying abnormality, genes change, and bacteria change.

Based on this, we have studied sixty cases of gallstones in this work. The contents of metal and non metal elements were analyzed, and the relationship between metals, non metals and gallstone formation was discussed. We hope to reveal the causes of gallstone formation and to provide inspiration for effective prevention and treatment of cholelithiasis in clinical medicine.

\section{Experimental Details}

\section{Reagents and Instruments}

Inductively coupled plasma emission spectrometer (ICP-AES, Optima 2000DV, Perkin Elmer, CT, USA). All conventional reagents used were analytically pure.

\section{Collection and Characterization of Gallstones}

Sixty cases of gallstones were obtained from surgery of Shenzhen People's Hospital, including 25 male and 35 female, aged between 24-71 years old, the average age is 43.9. The age and sex distribution in 60 patients with gallstones was showed in Figure 1. The stones were rinsed with water, then disinfected with $95 \%$ alcohol, after washed twice with deionized water, they were dried at $45^{\circ} \mathrm{C}$ in an oven and grinded into powder in a mortar. The component analysis by FT-IR indicated that 34 cases of gallstones were cholesterol type, 20 cases were pigment type, 4 cases were mixed type, and 2 cases were calcium carbonate type.

\section{Quantitative Analysis of Metal and Nonmetal Elements by ICP-AES}

$10.0 \mathrm{mg}$ gallstone samples were mixed with $3 \mathrm{~mL}$ concentrated $\mathrm{HNO}_{3}$ and $0.25 \mathrm{~mL}$ $\mathrm{HClO}_{4}$ solution for digestion. A separate $\mathrm{HClO}_{4}$ solution was heated until smoke appeared; the remaining heat was used to dry the solution. After cooled, $5 \mathrm{~mL}$ of $7 \%$ dilute $\mathrm{HNO}_{3}$ was added. An inductively coupled plasma emission spectrometer (ICPAES) was used to measure the concentration of calcium, zinc, copper, manganese, iron, magnesium, sulfur, and phosphorus.

\section{Statistical Analysis}

The experimental data were analyzed using SPSS version 16.0 software and expressed as the mean \pm standard deviation $\left(\bar{x}_{ \pm \mathrm{s}}\right) . \mathrm{p}<0.05$ was deemed to indicate a significant difference, $\mathrm{p}<0.01$ indicated an extremely significant difference, and $\mathrm{p}>0.05$ indicated no significant difference.

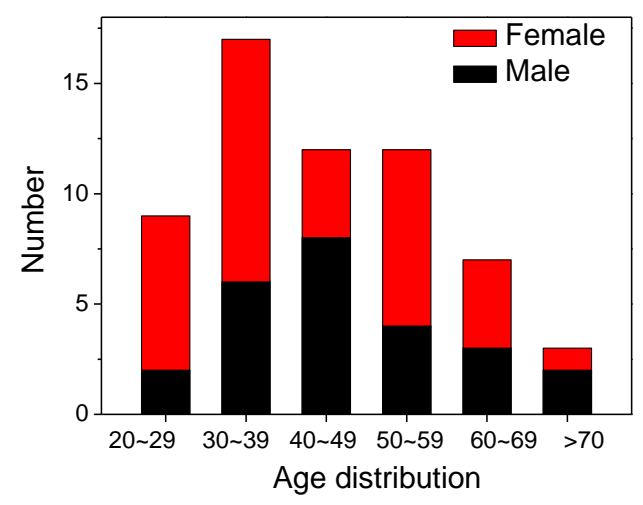

Figure. 1. Age and sex distribution of 60 cases of gallstones patients in Shenzhen area. 


\section{Results}

Major headings should be typeset in boldface with the first letter of important words capitalized.

\section{Contents of $\mathrm{Ca}, \mathrm{Mn}, \mathrm{Mg}, \mathrm{Fe}, \mathrm{Cu}, \mathrm{Zn}, \mathrm{S}$, and $\mathrm{P}$ in Gallstones}

The contents of $\mathrm{Ca}, \mathrm{Mn}, \mathrm{Mg}, \mathrm{Fe}, \mathrm{Cu}, \mathrm{Zn}, \mathrm{S}$, and $\mathrm{P}$ in 60 gallstones were analyzed using ICP-AES. The results are listed in Table 1. These gallstones included 34 cases of cholesterol type, 20 cases of pigment type, and 2 cases of calcium carbonate. The molecular structures of cholesterol and bilirubin are showed in Figure 2. The elements and contents of different kinds of stones were different. The statistical results showed that the contents of 8 kinds of ions in the pigment stones were higher than that in cholesterol gallstones, in which the contents of $\mathrm{Ca}, \mathrm{Cu}, \mathrm{S}$ and $\mathrm{P}$ have significant differences. It suggests that $\mathrm{Ca}, \mathrm{Cu}, \mathrm{S}$ and $\mathrm{P}$ play important roles in the formation of pigment stones. The higher contents of $\mathrm{Ca}$ and $\mathrm{Cu}$ ions were mainly related to the formation of bilirubinates of calcium and copper.

The content of various ions in mixed type stones and pigment stones is very similar, the reason of which is that the composition of mixed type stones and pigment stones is more similar. Calcium carbonate stones not only have higher calcium content, but also have lower the other ion content. That suggested that the main component is calcium carbonate.

Table 1. Contents of $\mathrm{Ca}, \mathrm{Mn}, \mathrm{Mg}, \mathrm{Fe}, \mathrm{Cu}, \mathrm{Zn}, \mathrm{S}$, and $\mathrm{P}$ in 60 gallstones detected using ICP-AES / mg/L

\begin{tabular}{llllll}
\hline $\begin{array}{l}\text { Type of } \\
\text { gallstones }\end{array}$ & $\begin{array}{l}\text { Cholesterol } \\
(1)\end{array}$ & $\begin{array}{l}\text { Pigment } \\
(2)\end{array}$ & $\begin{array}{l}\text { Mixed type } \\
(3)\end{array}$ & $\begin{array}{l}\text { Calcium } \\
\text { carbonate }\end{array}$ & $P$ \\
\hline $\mathrm{Ca}$ & $18.1 \pm 2.5$ & $47.1 \pm 1.2$ & $45.2 \pm 3.7$ & $39.4 \pm 10.4$ & $p_{1,2}<0.01 ; p_{1,3}<0.01$ \\
$\mathrm{Mn}$ & $0.12 \pm 0.02$ & $0.75 \pm 0.15$ & $1.55 \pm 0.67$ & $0.74 \pm 0.54$ & $p_{1,3}<0.05$ \\
$\mathrm{Mg}$ & $1.39 \pm 0.10$ & $4.10 \pm 0.34$ & $4.31 \pm 1.13$ & $2.10 \pm 0.58$ & $p_{1,2}<0.05 ; p_{1,3}<0.05$ \\
$\mathrm{Fe}$ & $1.55 \pm 0.05$ & $2.96 \pm 0.22$ & $2.05 \pm 0.22$ & $1.32 \pm 0.27$ & \\
$\mathrm{Cu}$ & $0.17 \pm 0.04$ & $3.66 \pm 0.49$ & $2.11 \pm 0.64$ & $1.31 \pm 0.69$ & $p_{1,2}<0.01 ; p_{1,3}<0.01$ \\
$\mathrm{Zn}$ & $0.11 \pm 0.01$ & $0.35 \pm 0.04$ & $0.22 \pm 0.03$ & $0.15 \pm 0.04$ & \\
$\mathrm{~S}$ & $2.33 \pm 0.32$ & $10.0 \pm 0.8$ & $7.26 \pm 2.24$ & $4.65 \pm 0.28$ & $p_{1,2}<0.01 ; p_{1,3}<0.05$ \\
$\mathrm{P}$ & $1.70 \pm 0.42$ & $4.99 \pm 2.35$ & $4.25 \pm 2.93$ & $2.55 \pm 0.59$ & $p_{1,2}<0.05 ; p_{1,3}<0.05$ \\
Percentage /\% & 2.55 & 7.39 & 6.70 & 5.22 & \\
\hline
\end{tabular}

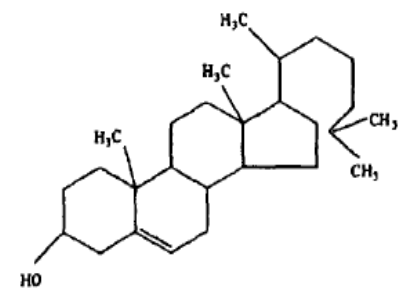

(a)

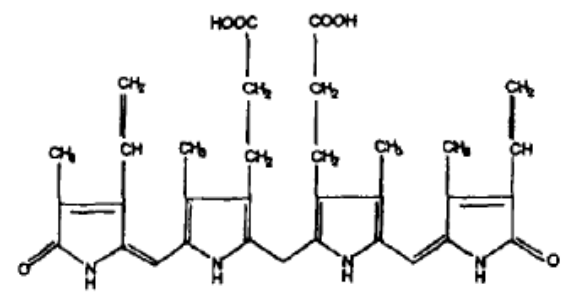

(b)

Figure. 2. Molecular structure of cholesterol (a) and bilirubin (b).

\section{Role of Metal and Nonmetal Ions in Gallstone Formation}

Gallstones include pigment type, cholesterol type, mixed type and other types. The major elements contained in the human body can be found in gallstones, and most of the trace elements that are essential to human body are also found in gallstones. 
However, the elements and their contents are different for different types of gallstones

Metal elements are generally found in the form of salts in gallstones. The content of copper in the black pigment stones was higher than that of the other types of stones, suggesting the copper salt (mainly copper bilirubinate) may play an important role in the formation of black stones. Calcium and sulfur were detected in every type of stones, and most of the gallstones have phosphorus. Phosphorus in gallstones is related to phosphates, and calcium is related to calcium salts. Sulfur element is generally related to proteins, which indicates that proteins play roles in gallstone formation. For cholesterol stones, the content of calcium in core is higher than that on the outer layer; but there is no significant difference in pigment stones. For mixed type gallstones, the content of calcium in core is higher than that in the middle and outer layer. We can obtain the following results from Table 1:

(1) The contents of various ions in cholesterol gallstones were low, and total content of all kinds of ions is only about $2.55 \%$ of stones. The concentrations of $\mathrm{Ca}$, $\mathrm{Cu}, \mathrm{S}$, and $\mathrm{P}$ in cholesterol gallstones are significantly less than that in pigment stones. Therefore, the nosogenesis of cholesterol gallstones is different from pigment stones. The pathogenesis of cholesterol gallstone is mainly because of cholesterol supersaturation, and metal ions play a smaller role in cholesterol gallstone formation. However, $\mathrm{Ca}, \mathrm{Cu}, \mathrm{S}, \mathrm{P}$ ions play important roles in formation of pigment gallstones.

(2) The content of calcium in pigment stones was significantly higher than that in cholesterol stones. The high content of calcium was related to the formation of complex calcium bilirubinate. The hydrolysis of bilirubin complexes induced by $\beta$ glucuronidase to produce unconjugated bilirubin (UCB), and UCB can combine with calcium ions to produce calcium bilirubinate, and then to form pigment gallstones [6]. Calcium bilirubinate complex is one of the major components of pigment gallstone. The $\mathrm{NH}$ groups of pyrrol ring and the inner amide ring in bilirubin can coordinate with $\mathrm{Ca}^{2+}$ ions, and the formed bilirubin complexes are connected by Ca-bridge and $\mathrm{H}$-bond. Due to the diversity coordination of calcium and bilirubin, calcium bilirubinate has the characteristics of non stoichiometry.

The copper content in pigment stones is also significantly higher than that in cholesterol stones, which shows that copper salts play important role in pigment stones. $\mathrm{Cu}^{2+}$ ion can coordinate with $\mathrm{N}$ atom in pyrrole ring and the lactam ring to form copper bilirubinate complex; meanwhile, under the catalysis of $\mathrm{Cu}^{2+}$ ion, bilirubin was oxidized by free radical, and then bilirubin was crossed as a polymer with a large conjugated system by Ca-bridge, thus make pigment stones present deep black appearance.

(3) The contents of various ions in mixed-type stones are similar to those of pigment stones because of the similar components of the two types of stones. Cholesterol can often be detected in the core of mixed-type stones, while the outer layer is composed of calcium bilirubinate and calcium carbonate. After cholesterol core was formed, $\mathrm{Cu}^{2+}$ and $\mathrm{Ca}^{2+}$ ions can act with bile pigment, then making calcium bilirubinate deposited, and finally the mixed-type cholesterol-pigment gallstones was formed.

(4) For calcium carbonate stones, calcium content is much higher, but the contents of the other ions are low. It suggests that their main components are calcium carbonate. Carbonate in bile can react with the high concentration of $\mathrm{Ca}^{2+}$ ions, then insoluble calcium carbonate was formed. Calcium carbonate in human gallstones generally showed as calcite structure. High concentration of $\mathrm{Ca}^{2+}$ ions can also react with certain proteins, which promoting the formation of gallstones.

(5) The contents of $\mathrm{P}$ and $\mathrm{S}$ in pigment stones were significantly higher than those 
in cholesterol stones, which suggested that proteins had a role in the formation of stones, especially the pigment gallstones. Some proteins (such as mucoproteins) can promote nucleation in the formation process of pigment gallstone [7]. For example, the mucoproteins 1 (MUC1) expression of gallstone patients, especially for patients with calcium bilirubinate gallstones, is high than that of normal people. High expression of mucoprotein implies the increase of gallstone risk. Excessive secretion of mucoprotein can constitute a stone mesh scaffolds, bile pigment and calcium carbonate particles can gather to precipitate in the mesh.

\section{Conclusions}

In this paper, the contents of $\mathrm{Ca}, \mathrm{Mn}, \mathrm{Mg}, \mathrm{Fe}, \mathrm{Cu}, \mathrm{Zn}, \mathrm{S}$, and $\mathrm{P}$ in 60 cases of gallstones in Shenzhen area were measured by ICP-AES. $\mathrm{Ca}, \mathrm{Cu}, \mathrm{S}$ and $\mathrm{P}$ play important roles in formation of pigment gallstones. High concentrations of $\mathrm{Ca}^{2+}$ and $\mathrm{Cu}^{2+}$ ions are closely related to the formation of calcium bilirubinate and copper bilirubinate complexes. Phosphorus and sulfur elements showed the existence of proteins, and certain proteins (such as mucins) can promote nucleation in the process of gallstone formation. The content of metal ions is low in cholesterol gallstones, whose pathogenesis is mainly due to the increase of biliary cholesterol secretion. The content of various ions in mixed-type stones are similar to that of pigment stones. Except the higher content of calcium, the other ions in calcium carbonate gallstones are much lower. The analysis of metal and nonmetal ions in gallstones is of great significance to reveal the cause of gallstones formation. This study can provide inspiration for effective prevention and treatment of cholelithiasis in clinical medicine.

\section{Acknowledgments}

This work is supported by Scientific research project of Health and Family Planning Commision of Shenzhen Municipality in 2015 (NO: 201501004)

\section{References}

[1] X.Y. Song, S. Xu, J.F. Hu, J. Tang, S.F. Chu, H. Liu and N.H. Chen, Piperine prevents cholesterol gallstones formation in mice, Eur. J. Pharmacol. 751, 112 (2015).

[2] D. Teilum, The prevalence of gallstones in autopsies from a Danish urban area, Acta. Chir. Scan. 155, 103 (1989).

[3] D. Zhang, J. Xiang, L. Wang, Z. Xu, L. Sun, F. Zhou and D. Cai, Comparative proteomic analysis of gallbladder bile proteins related to cholesterol gallstones, PloS one. 8, e54489 (2013).

[4] Z.H. Yang, K. Wang and X.T. Liu, Studies of electron spin resonance on bilirubin free radicals, Science in China. 35, 1093 (1992).

[5] J.R. Ferraro, J.G. Wu, R.D. Soloway, W.H. Li, Y.Z. Xu, D.F. Xu and G.R. Shen, Copper binding to bilirubin as determined by FT-IR and EPR spectroscopy. Appl. Spectrosc. 50, 922 (1996).

[6] L. Stewart, R. Ponce, A.L. Oesterk, J.M. Griffiss and L.W. Way, Pigment gallstone pathogenesis: slime production by biliary bacteria is more important than beta-glucuronidase production, J. Gastrointest. Surg. 4, 547 (2000). 
[7] S.B. Ho, L.L. Shekels, N.W. Toribara, I.K. Gipson, Y.S. Kim, P.P. Purdum and D.L. Cherwitz, Altered mucin core peptide expression in acute and chronic cholecystitis, Digest. Dis. Sci. 45, 1061 (2000). 